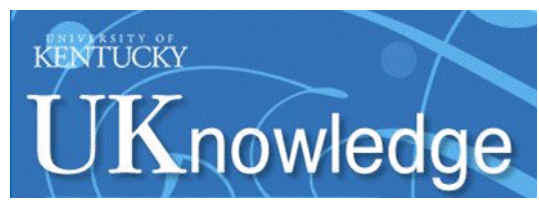

University of Kentucky

UKnowledge

\title{
Trait-Based Profiles of ADHD in Adolescents and Young Adults
}

Tess E. Smith

University of Kentucky, tesm223@g.uky.edu

Digital Object Identifier: http://dx.doi.org/10.13023/ETD.2016.268

Right click to open a feedback form in a new tab to let us know how this document benefits you.

\section{Recommended Citation}

Smith, Tess E., "Trait-Based Profiles of ADHD in Adolescents and Young Adults" (2016). Theses and Dissertations--Psychology. 93.

https://uknowledge.uky.edu/psychology_etds/93

This Master's Thesis is brought to you for free and open access by the Psychology at UKnowledge. It has been accepted for inclusion in Theses and Dissertations--Psychology by an authorized administrator of UKnowledge. For more information, please contact UKnowledge@lsv.uky.edu. 


\section{STUDENT AGREEMENT:}

I represent that my thesis or dissertation and abstract are my original work. Proper attribution has been given to all outside sources. I understand that I am solely responsible for obtaining any needed copyright permissions. I have obtained needed written permission statement(s) from the owner(s) of each third-party copyrighted matter to be included in my work, allowing electronic distribution (if such use is not permitted by the fair use doctrine) which will be submitted to UKnowledge as Additional File.

I hereby grant to The University of Kentucky and its agents the irrevocable, non-exclusive, and royalty-free license to archive and make accessible my work in whole or in part in all forms of media, now or hereafter known. I agree that the document mentioned above may be made available immediately for worldwide access unless an embargo applies.

I retain all other ownership rights to the copyright of my work. I also retain the right to use in future works (such as articles or books) all or part of my work. I understand that I am free to register the copyright to my work.

\section{REVIEW, APPROVAL AND ACCEPTANCE}

The document mentioned above has been reviewed and accepted by the student's advisor, on behalf of the advisory committee, and by the Director of Graduate Studies (DGS), on behalf of the program; we verify that this is the final, approved version of the student's thesis including all changes required by the advisory committee. The undersigned agree to abide by the statements above.

Tess E. Smith, Student

Dr. Michelle M. Martel, Major Professor Dr. Mark Fillmore, Director of Graduate Studies 
TRAIT-BASED PROFILES OF ADHD IN ADOLESCENTS AND YOUNG ADULTS

\section{THESIS}

A thesis submitted in partial fulfillment of the requirements for the degree of Master of Science in the College of Arts and Sciences at the University of Kentucky

By

Tess E. Smith

Director: Dr. Michelle M. Martel, Professor

of Psychology

Lexington, KY

2016

Copyright (C) Tess E. Smith 2016 


\section{ABSTRACT OF THESIS}

\section{TRAIT-BASED PROFILES OF ADHD IN ADOLESCENTS AND YOUNG ADULTS}

Empirical work has examined the utility of using person-centered statistical approaches emphasizing traits to parsing Attention-Deficit/Hyperactivity disorder (ADHD) heterogeneity in preschool and school-aged children. However, trait-based profiles have not yet been examined in other age ranges, specifically adolescence and young adulthood. Therefore, the goal of the present study is to examine trait-based profiles in adolescents and young adults with ADHD in order to evaluate their similarity with trait-based profiles in preschoolers and children with ADHD and through comparison with external correlates (e.g., comorbidity). One hundred and eighty-two adolescents and 287 young adults completed measures of ADHD symptoms, personality and temperament traits, and comorbid internalizing and externalizing problems. Latent profile analysis suggested at least three consistent trait-based profiles related to ADHD within adolescents and young adults: low extraversion, high extraversion, and high neuroticism profiles. These profiles were largely similar to those found in preschool and middle childhood and demonstrated similar comorbidity patterns; namely, the low extraversion profile exhibited higher internalizing problems, the high extraversion profile exhibited higher externalizing problems, and the small high neuroticism profile exhibited descriptively higher levels of all comorbid problems. Such profiles may have utility for personalization of intervention based on trait profiles and comorbidity patterns, as well as - more speculatively - possible prognostic utility. 
TRAIT-BASED PROFILES OF ADHD IN ADOLESCENTS AND YOUNG ADULTS

By

Tess E. Smith

Michelle Martel, Ph.D. Director of Thesis

Mark Fillmore, Ph.D. Director of Graduate Studies

May 31, 2016 


\section{TABLE OF CONTENTS}

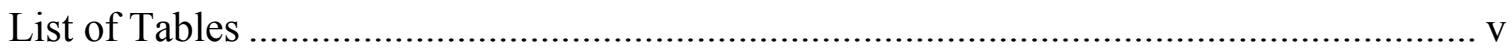

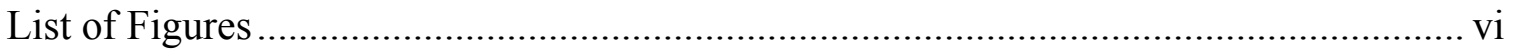

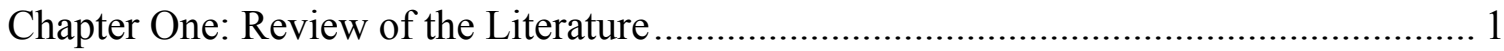

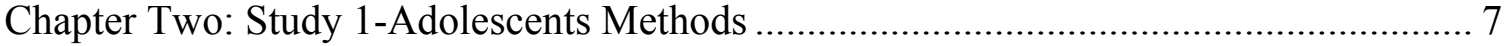

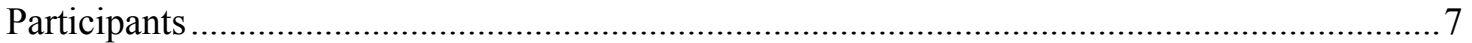

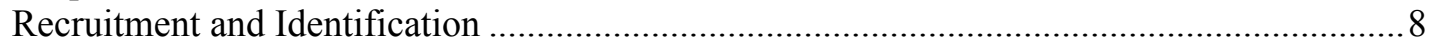

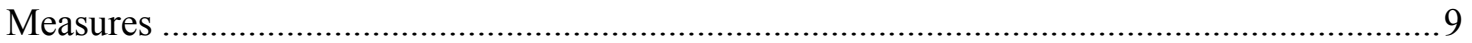

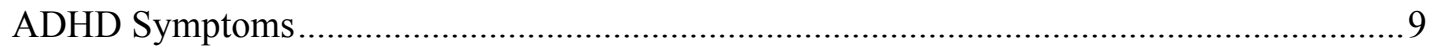

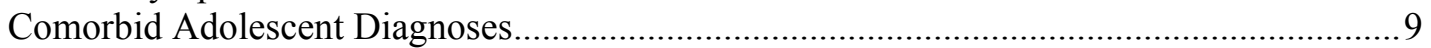

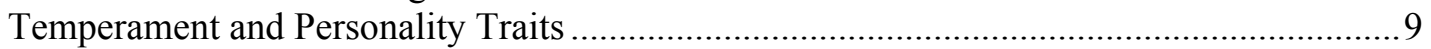

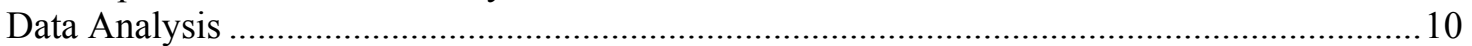

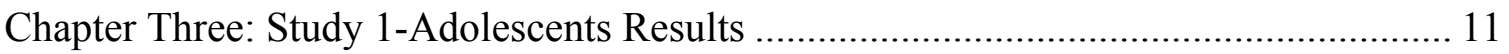

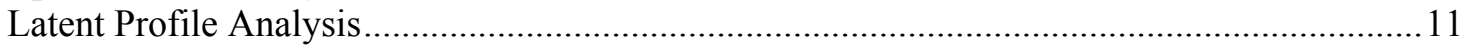

Comparison with Preschool and Childhood Profiles .............................................................. 12

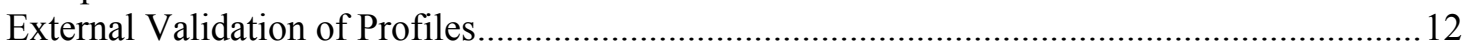

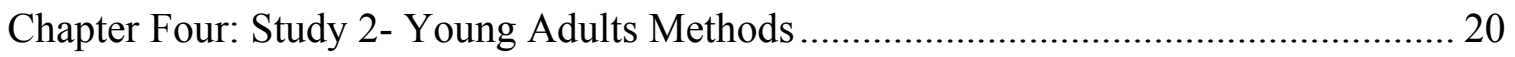

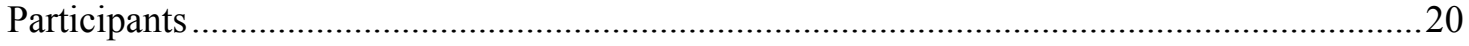

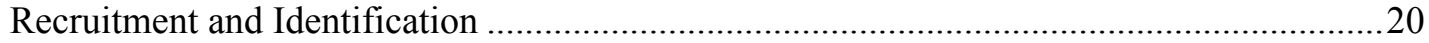

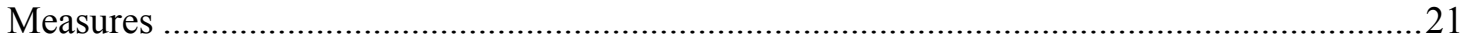

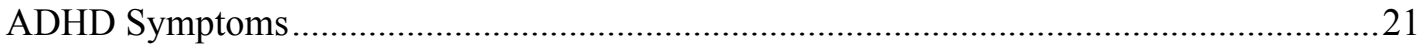

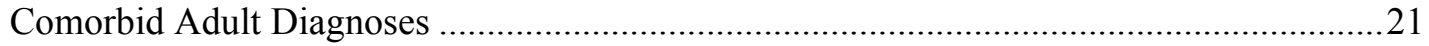

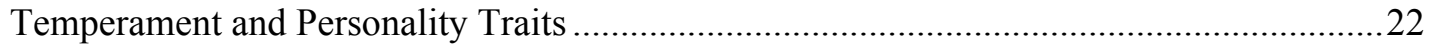

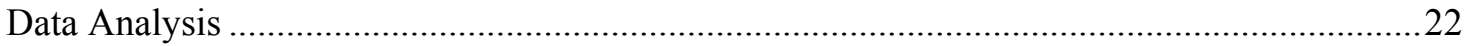

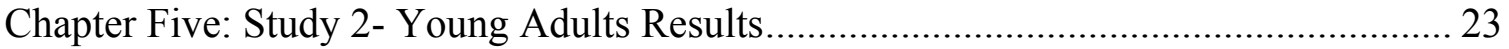

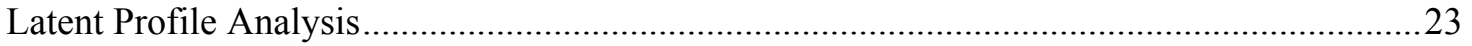

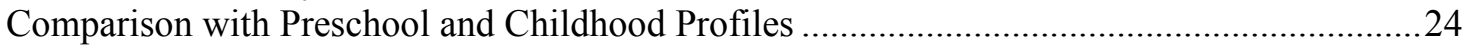

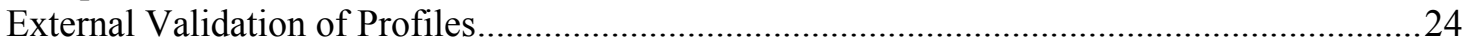

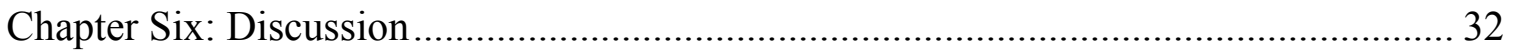

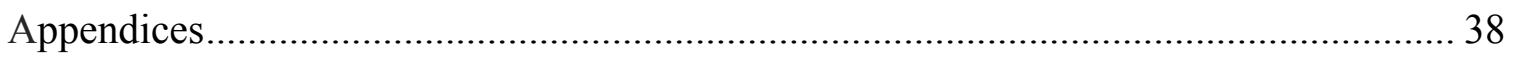

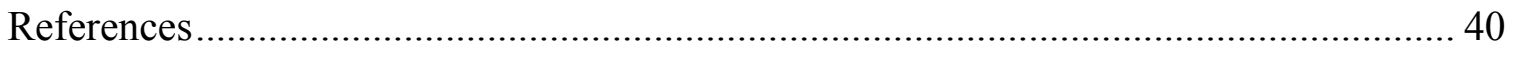

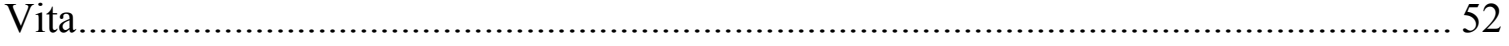




\section{LIST OF TABLES}

Table 1 Latent Profile Analysis Fit Indices: Adolescents.............................15

Table 2 Latent Profile Solutions Using Adolescent Traits: Descriptive Statistics....... 16

Table 3 Adolescent External Validation: Five Profiles.............................17

Table 4 Comparisons of Relative Percentage of Individuals Falling into Each Profile

Through Adolescence.......................................................... 18

Table 5 Latent Profile Analysis Fit Indices: Young Adults.............................27

Table 6 Latent Profile Solutions Using Young Adult Traits: Descriptive Statistics......28

Table 7 Young Adult External Validation: Five Profiles............................29

Table 8 Comparisons of Relative Percentage of Individuals Falling into Each Profile.

Through Young Adulthood.................................................... 30 


\section{LIST OF FIGURES}

Figure 1 Five-profile solution in Adolescents...................................... 19

Figure 2 Five-profile solution in Young Adults.................................... 31 


\section{Trait-based Profiles of ADHD in Adolescents and Young Adults}

\section{Chapter One: Review of the Literature}

Attention-Deficit/Hyperactivity disorder (ADHD) is a neurodevelopmental disorder that begins early and is characterized by symptoms of inattention and/or hyperactivityimpulsivity, according to the Diagnostic and Statistical Manual of Mental DisordersFifth Edition (DSM-5; APA, 2013). ADHD affects about 5\% of children and $2.5 \%$ of adults across most cultures (Polanczyk et al., 2007). Furthermore, ADHD is associated with substantial societal costs including treatment, other health care costs, and educational and legal expenses (Pelham, Foster, \& Robb, 2007). In addition, individuals with ADHD exhibit difficulties with academic achievement, social relationships, comorbidity, accidental injury or death, and higher rates of unemployment and divorce as adults (reviewed by Barkley, 2014).

Although ADHD was historically considered a childhood disorder, current work validates it into adulthood (Biederman et al., 2010; Faraone et al., 2005). Yet prominent developmental changes in symptoms occur (e.g., hyperactivity declines after preschool; Hart et al., 1995; Lahey et al., 2005; Martel, von Eye, \& Nigg, 2012). In addition to developmental change in symptomatology, there is substantial inter-individual heterogeneity in the symptom presentation of those diagnosed with ADHD, historically labeled with subtypes (DSM-IV-TR, 2000). DSM-5 distinguishes three subtypes, or presentations: predominantly inattentive presentation (i.e., six or more symptoms of inattention), predominately hyperactive/impulsive presentation (i.e., six or more symptoms of hyperactivity-impulsivity, and combined (i.e., six or more symptoms in both domains; APA, 2013). Yet, these subtypes have failed to demonstrate external 
validity in that they lack temporal stability (Lahey et al., 2005) and do not have distinct external correlates (Nigg et al., 2002; Chhabildas, Pennington, \& Willcutt, 2001). Furthermore, the DSM-5 presentations do not exhibit distinct neuropsychological or neurobiological patterns (Chhabildas, Pennington, \& Willcutt, 2001; Fair et al., 2012; Nigg et al., 2005). For this reason, it has been suggested that some subtypes might be better broken down into additional groups such as a restrictive inattentive subtype (six or more symptoms of inattention and two or fewer hyperactive-impulsive symptoms; GothOwens et al., 2010) or sluggish cognitive tempo (inconsistent alertness or orientation characterized by sluggishness, drowsiness, and apparent daydreaming; Barkley, 2012; McBurnett, Pfiffner \& Frick, 2001). Yet, this work remains inconclusive and, for that reason, was not included in DSM-5.

An alternative and particularly promising method of subtyping ADHD involves temperament and personality trait profiles, consistent with the new National Institute of Mental Health (NIMH) Research Domain Criteria (RDoC) initiative, which seeks to develop a research classification of mental disorders based on dimensions of neurobiology and psychology, including affect and behavior (Insel et al., 2010). Such a continuous approach integrating affective traits would allow for more powerful study of normal and abnormal behavior and the continuum in between, as well as allowing more sensitive tracking of developmental changes in behavior and neurobiology. Temperament traits provide one means by which to sensitively track developmental changes in behavior as they are defined as individual differences in reactivity and self-regulation (Rothbart, 1991). Historically, temperament has been viewed as being primarily inherited, or biological, in nature (Frick, 2004; Rothbart, 1989). Personality traits, on the other hand, 
have been defined as individual differences in characteristic ways of behaving, thinking, and feeling (McCrae \& Costa, 1987; Tackett, 2006) that are more heavily influenced by the environment as development takes place. Despite temperament and personality historically being distinguished from one another, recent work has suggested that they both measure similar traits that are both approximately equally influenced by genes and aspects of the environment (e.g., Hopwood et al., 2012; Silberg et al., 2005). Theoretical and empirical work both suggest that temperament and personality traits are highly related to one another (theoretical: Tackett, 2006; Shiner \& Caspi, 2003; empirical: De Pauw et al., 2009).

In line with this idea, collapsing across the most well validated trait models, at least three common higher-order traits emerge: Negative affect, or neuroticism; surgency or extraversion; and effortful control, or conscientiousness (De Fruyt et al., 2006; Shiner \& Caspi, 2003). Negative affect (or neuroticism) refers to lower-order traits such as anger, sadness, fear, physical discomfort, and recovery from distress. Surgency (or extraversion) refers to activity level, sociability, and pleasure expressed in anticipation of reward or during high-intensity activities. Effortful control (or conscientiousness) includes the ability to focus attention and, in older children, to exercise inhibitory control (McCrae \& Costa, 1987; Rothbart, 1989). In addition to these three common higher-order traits, it is also important to consider agreeableness. Agreeableness is characterized by altruism, trust, compliance, and concern (McCrae \& Costa, 1987). Studies have noted that, at lower levels of hierarchical models, agreeableness emerges from higher-order negative affect and effortful control factors, perhaps being most associated with effortful control (Nigg, 2006; Markon, Krueger, \& Watson, 2005). 
Although traits are believed to be relatively stable, changes in traits may occur throughout critical points in development (Costa, McCrae, \& Siegler, 1999; McCrae et al., 2002; Roberts \& DelVicchio, 2000). For example, during the transition from late childhood to adolescence negative affect increases in females, while effortful control increases in young adulthood; surgency and agreeableness tend to remain more stable, particularly during adulthood (McCrae et al., 2002; Roberts, Walton, \& Viechtbauer, 2006).

There is a growing body of research demonstrating that temperament and personality traits relate to psychopathology and ADHD in particular. Reviewing this body of work, Martel (2009) concluded that, as an overall group, children with ADHD exhibit high levels of negative affect and low levels of control. However, examining ADHD symptom domains reveal more specific associations (Martel, 2009). Inattentive symptoms appear to be primarily associated with effortful control, while hyperactive-impulsive symptoms appear to be primarily associated with extraversion (Martel \& Nigg, 2006; Martel, 2009) Research also suggests that associations between temperament traits and ADHD may change throughout development. In childhood, ADHD symptoms are associated with lower effortful control. However, increased levels of negative affect and lower levels of agreeableness predict increasing levels of ADHD symptoms into adolescence and young adulthood, again with low effortful control related to the inattentive symptom domain and low agreeableness associated with the hyperactive-impulsive symptom domain (Miller et al., 2007; Nigg et al., 2002). Thus, overall, ADHD is associated with low effortful control, low agreeableness, and increased levels of negative affect with low effortful control particularly associated with inattentive ADHD symptoms during childhood and 
high negative affect, low agreeableness associated with symptoms persisting into adolescence and adulthood, particularly hyperactivity-impulsivity.

Interestingly, research suggests traits may be part of the pathway to psychopathology (Martel, 2009), although the nature of associations between traits and psychopathology are still debated (Nigg, 2006; Tackett, 2006). To date, a number of different models of these associations have been proposed, with two particularly prominent: the vulnerability model and the spectrum model (De Bolle, Beyers, W., De Clercq, \& De Fruyt, 2012; Van Leeuwen et al., 2007). The vulnerability model theorizes that temperament traits might make individuals more vulnerable to psychopathology. In contrast, the spectrum model suggests that psychopathology and traits lie on the same continuum, with psychopathology being synonymous with extreme temperament-based traits (i.e., ADHD as a disorder of extreme low effortful control; Nigg, 2006; Shiner \& Caspi, 2003; Tackett, 2006). Regardless of the particular model endorsed, traits seem to relate to psychopathology in a meaningful way in that extreme traits can predict the onset of psychopathology in young children. Thus, early temperament traits might be useful for identifying and predicting the course of psychopathology.

Current research has started to recognize the utility of this approach in relation to childhood behavioral disorders, including ADHD. Theory has suggested several possible pathways to ADHD (Martel, 2009; Nigg et al., 2004). For example, children characterized by low effortful control may be predisposed to develop inattentive symptoms of ADHD, while children characterized by high emotionality, high surgency, and low agreeableness may be predisposed to develop hyperactive-impulsive symptoms, 
with those high in negative affect being predisposed to comorbid ODD or CD symptomology.

Empirical work has examined the utility of using such an approach to parsing ADHD heterogeneity using person-centered statistical approaches in school-aged and preschool children (Karalunas et al., 2014; Martel, in press; Martel, Goth-Owens, Martinez-Torteya, and Nigg, 2010). In a cross-sectional sample of school-aged children, three distinct traitbased groups were found: a low control group, a high surgency group, and a low surgency/high negative affect group. The low control group exhibited increased rates of comorbid ODD, disruptive behavior, and mood/anxiety problems (Martel, Goth-Owens, Martinez-Torteya, and Nigg, 2010). These three trait-based subgroups were replicated in a longitudinal school-aged sample, which found the high negative affect group exhibited doubled rates of onset for new behavioral and emotional disorders at the one-year followup (Karalunas et al., 2014). Furthermore, over the one-year follow-up trait-based profiles were found to be the best predictor of later comorbid disorders, compared to ODD symptom status, and DSM-5 ADHD presentations (Karalunas et al., 2014). Similarly, in a preschool sample, ages 3 to 6 , over-recruited for clinical cases, three distinct trait-based subgroups were found: a low control group, a high surgency group, and a high negative affect group. The high surgency group, in particular, was at increased risk for comorbid psychopathology and worsening symptoms over a 6-month follow-up (Martel, in press). Overall, cross-sectional and longitudinal samples of school-aged children with ADHD and preschoolers with ADHD appear to be described by three distinct trait-based groups: low effortful control, high surgency, and high negative affect. This body of research 
supports the idea that a person-centered approach to subtyping ADHD may have utility for clinical prediction of the course of ADHD.

Despite this research suggesting somewhat similar trait profiles in preschoolers and children with ADHD, trait-based profiles have not yet been examined in other age ranges, specifically adolescence and young adulthood. Therefore, the goal of the present study was to examine trait-based profiles in adolescents and young adults with ADHD in order to evaluate their similarity with trait-based profiles in preschoolers and school-age children and to externally validate these profiles in adolescence and young adulthood through comparison with external correlates (e.g., comorbidity). It was hypothesized that, within adolescents and young adults with ADHD, similar three trait-based profiles (i.e., low control, high positive affect, high negative affect) would emerge as seen in preschool and childhood. However, it was predicted that a relatively larger percentage of adolescents and young adults would be characterized by negative affect and fall into the high negative affect subgroup during adolescence and young adulthood compared to preschool and childhood due to normative developmental increases in negative affect.

\section{Chapter Two: Study 1-Adolescents Methods}

\section{Participants}

Adolescent sample participants were 182 youth (103 males) age 13 to 17 years. Nineteen percent identified themselves as ethnic minorities. Adolescents were included in one of two groups: those diagnosed with ADHD, any type $(n=83)$, and controls $(n=99)$. The ADHD group included 42 ADHD-Predominantly Inattentive and 41 ADHDCombined type. Twenty-two adolescents met criteria for Oppositional/Defiant Disorder; four for Conduct Disorder. 


\section{$\underline{\text { Recruitment and Identification }}$}

For the adolescent sample, a broad community recruitment strategy was used, with mass mailings to parents in local school districts and public advertisements, in order to obtain as broadly representative of a sample as possible. Families initially recruited then passed through a standard multi-gate screening process to establish diagnostic groupings. At Stage 1, all families $(\mathrm{N}=672)$ were screened by phone to rule out youth prescribed long-acting psychotropic medication (e.g. antidepressants), neurological impairments, seizure history, head injury with loss of consciousness, other major medical conditions, or a prior diagnosis of mental retardation or autistic disorder, as reported by the parent.

At Stage 2, parents and teachers or remaining eligible youth $(N=469)$ completed rating scales (Child Behavior Checklist [CBCL; Achenbach, 1991], Conners Parent and Teacher Rating Scales [Conners, 1997], ADHD Rating Scale [DuPaul et al., 1998]). Parents completed a structured clinical interview, and children completed IQ and achievement testing. Families were screened out here if they fail to attend the diagnostic visit or if teacher ratings cannot be obtained.

Youth and their primary caregiver completed the Kiddie Schedule for Affective Disorders-Epidemiologic Version (KSADS-E; Puig-Antich and Ryan 1986). The data from the interviews and parent and teacher rating scales were presented to a clinical diagnostic team consisting of a board certified child psychiatrist and licensed clinical child psychologist. Their agreement rates were acceptable for ADHD diagnosis, subtypes, and current ODD and CD (all kappas $\geq .89$ ). 
All youth then came back for a second laboratory visit a few weeks later during which time parents completed temperament measures, and youth completed neuropsychological measures.

\section{$\underline{\text { Measures }}$}

\section{$\underline{\text { ADHD Symptoms }}$}

Adolescents completed the age appropriate version of the ADHD rating scale (DuPaul et al., 1998). The rating scale includes 18 items that are consistent with DSM-IV diagnostic criteria for ADHD. Participants used a 4-point Likert scale, ranging from 0 (Never or rarely) to 3 (Very often), to rate their symptom severity and level of impairment over the past 6 months. Total, inattentive, and hyperactive-impulsive symptom sums will be used.

\section{Comorbid Adolescent Diagnoses}

The Youth Self-Report (YSR; Achenbach, 1991) is used to assess social and emotional functioning in adolescents ages 11-18. This instrument yields reliable and valid standardized scores on 10 subscales (i.e., withdrawn, somatic complaints, anxious /depressed, social problems, thought problems, attention problems, delinquent behavior, aggressive behavior, externalizing and internalizing behavior) and a total behavior problems score. Both raw and t-scores will be utilized.

\section{Temperament and Personality Traits}

To assess temperament and personality traits, parents completed the California Child Q-Sort (CCQ), specifically the common language version (Caspi et al. 1992). The CCQ is a typical Q-Sort consisting of 100 cards which must be placed in a forced-choice, nine-category, rectangular distribution. The rater (in this case, the mother) described the 
adolescent by placing descriptive cards in one of the categories, ranging from one (least descriptive) to nine (most descriptive). Thus, items at the extreme ends of this range are most descriptive. Instructions were derived from the standard instruction set provided by Jack Block (personal communication, 1996). To measure negative emotionality, resiliency, and reactive control, scales developed by Eisenberg et al. (1996; 2003; personal communication, 2006) were used (e.g., reactive control, "is shy and reserved;" resiliency, "is resourceful in initiating activities;" negative emotionality, "cries easily"). To measure the Big Five, scales developed by John and colleagues (1994) were used (e.g., neuroticism, "tends to brood and ruminate;" agreeableness, "is eager to please;" conscientiousness, "is competent, skillful"). Items from these scales were averaged after reverse-scoring selected items. Higher scores reflect higher average levels of the relevant trait.

\section{$\underline{\text { Data Analysis }}$}

Latent profile analysis models fitting $1-5$ profile solutions were conducted in Mplus in order to identify temperament/personality groups within ADHD. In the adolescent sample, there was no missing data. Latent profile analysis was conducted on negative emotionality, neuroticism, extraversion, conscientiousness, agreeableness, and openness. Model fit was compared using log likelihood, Akaike information criteria (AIC), Bayes information criteria (BIC), and entropy, as is recommended (Grant et al., 2006). Smaller

values of log likelihood, AIC, and BIC indicate better fit to the data, and higher values of entropy reflect better distinctions between groups (Kline, 2005). Examination of relative percentages of individuals falling into subgroups in adolescence, compared to preschool and childhood, was evaluated using chi-square statistics. External validation of the best- 
fitting profile solution in adolescence was conducted using multivariate general linear models (GLMs), examining profiles differences in ADHD symptoms, and comorbid internalizing and externalizing problems, followed by corrected least significant difference (LSD) post hoc analyses, which control for Type I error (Tabachnick \& Fidell, 2007).

\section{Chapter Three: Study 1-Adolescents Results}

\section{$\underline{\text { Latent Profile Analysis }}$}

Latent profile models containing one through five profiles were fit to all traits to exhaust the available models. Significant improvements in fit occurred as the number of profiles increased up to four profiles, at which point log likelihood and AIC continued to improve, while BIC and entropy leveled off (Table 1). While both four and five profile solutions were supported, based on a preponderance of these fit indices, based on theoretical considerations, the five profile solution was chosen as the focus of the current study, due to its similarity to prior work in preschool and childhood (but see four-profile solution results in the appendix).

Descriptive statistics for personality traits within each profile for each solution are shown in Table 2 and depicted graphically in Figure 1. As shown in Table 2 and Figure 1, Profile 1 ( $n=97$ ) was labeled "low neuroticism," based on its descriptively lower levels of negative emotionality and neuroticism, as well as higher levels of agreeableness and conscientiousness. Profile $2(n=25)$ was characterized by low levels of conscientiousness, as well as lower levels of agreeableness and openness, and was labeled "low conscientiousness." Profile $3(n=27)$ was labeled "low extraversion," as relatively lower levels of extraversion characterized this group. Profile $4(n=30)$ was 
labeled "high extraversion," as relatively higher levels of extraversion characterized this group. Profile $5(n=3)$ exhibited relatively higher levels of negative emotionality and neuroticism and was labeled "high neuroticism."

As shown in Table 3, the percentage of adolescents with ADHD within group significantly varied across the five profiles, $\chi^{2}(4)=76.21, p=.000$; adolescents in the low conscientiousness, low extraversion, high extraversion, and high neuroticism profiles were particularly likely to be diagnosed with ADHD compared with the low neuroticism profile, based on over half $(50 \%)$ of each group being characterized by a diagnosis of ADHD.

\section{Comparison with Preschool and Childhood Profiles}

As shown in Table 4, the relative percentage of individuals falling into each profile significantly varied across preschool, middle childhood, and adolescence, $\chi^{2}(8)=$ $49.65, p=.000$. Based on study hypotheses that a relatively larger percentage of individuals would fall into the high neuroticism group in adolescents, compared to preschool and childhood, targeted posthoc comparisons were examined for the high neuroticism profile between preschool and adolescence, $\chi^{2}(1)=15.53, p=.000$, and between middle childhood and adolescence, $\chi^{2}(1)=2.41, p=.12$. These results suggest that, counter to hypotheses, there were significantly lower percentage of individuals in the high neuroticism group during adolescence compared to during preschool.

\section{$\underline{\text { External Validation of Profiles }}$}

The profiles were next externally validated via a series of multivariate GLMs that examined adolescent profile differences in self-reported 1) ADHD symptoms and 2) comorbid internalizing and externalizing problems. The overall multivariate GLM 
examining adolescent profile differences in self-reported inattention and hyperactivityimpulsivity was significant, $F(8,342)=9.54, p=.000$. Individual GLMs identified significant differences in both self-report inattentive symptoms, $F(4,171)=15.20, p=$ .000 , and hyperactive-impulsive symptoms, $F(4,171)=15.20, p=.000$. Based on posthoc least significant difference (LSD) tests, the low neuroticism group had significantly lower levels of inattentive symptoms, compared to all other groups, and the low neuroticism and low extraversion groups exhibited lower levels of hyperactive-impulsive symptoms (Table 3). The low conscientiousness and high extraversion profiles exhibited relatively higher levels of both inattentive and hyperactive-impulsive symptoms. Although the high neuroticism profile did not significantly differ from the other profiles in symptoms (likely because such a small number of individuals fell into that profile), descriptively the high neuroticism profile exhibited the highest mean-level of both inattentive and hyperactive-impulsive symptoms. Overall, the low conscientiousness and high extraversion profiles exhibited higher levels of ADHD symptoms of both inattention and hyperactivity-impulsivity, while the low extraversion profile exhibited higher levels of just inattentive symptoms, compared to the other profiles.

The overall multivariate GLM examining adolescent profile differences in comorbid self-report internalizing and externalizing problems was also significant, $F(52$, $520)=2.09, p=.000$. Individual GLM identified significant differences in activity, $F(4$, $139)=3.63, p=.008$, attention problems, $F(4,139)=6.18, p=.000$, aggressive behavior, $F(4,139)=7.35, p=.000$, and rule-breaking behaviors, $F(4,139)=6.89, p=$ .000. Based on post-hoc LSD tests, the low conscientiousness, high extraversion, and high neuroticism groups exhibited relatively higher levels of aggressive behavior and 
rule-breaking compared to the other profiles. Although the high neuroticism profile had the highest mean level attention problems and rule-breaking behaviors, as shown in Table 3 , these differences were not always significant (likely due to the small number of individuals that fell into the high neuroticism profile). The low extraversion profile exhibited relatively lower levels of activity and the low neuroticism group exhibited relatively lower levels of attention problems, compared to the other profiles. Overall, the low conscientiousness and high extraversion profiles exhibited greater comorbid externalizing problems, and the low conscientiousness profile additionally exhibited greater attention problems. The low extraversion profile exhibited increased comorbid withdrawal/depression, while the low neuroticism profile exhibited relatively fewer comorbid problems. 
Table 1.

Latent Profile Analysis Fit Indices: Adolescents

\begin{tabular}{llccc}
\hline Profile & Log likelihood & AIC & BIC & Entropy \\
\hline 1-profile & -1804.220 & 3632.440 & 3670.888 & ----- \\
2-profile & -1709.370 & 3456.740 & 3517.616 & 0.849 \\
3-profile & -1676.401 & 3404.802 & 3488.106 & 0.889 \\
4-profile & -1653.842 & 3373.685 & 3479.417 & 0.891 \\
5-profile & $\mathbf{- 1 6 4 0 . 6 3 0}$ & $\mathbf{3 3 6 1 . 2 6 0}$ & $\mathbf{3 4 8 9 . 4 2 0}$ & $\mathbf{0 . 8 3 4}$ \\
\hline
\end{tabular}

Note. AIC $=$ Akaike's information criteria; $\mathrm{BIC}=$ Bayes information criteria. Boldface indicates the best-fitting models. 
Table 2.

Latent Profile Solutions Using Adolescent Traits: Descriptive Statistics

\begin{tabular}{|c|c|c|c|c|c|c|c|}
\hline Solution & $n$ & $\mathrm{NE}$ & $\mathrm{N}$ & $\mathrm{E}$ & $\mathrm{O}$ & $\mathrm{A}$ & $\mathrm{C}$ \\
\hline \multicolumn{8}{|c|}{ Five-profile solution } \\
\hline Profile 1 & 97 & 2.969 & 3.366 & 5.415 & 5.997 & 6.904 & 6.572 \\
\hline Profile 2 & 25 & 5.028 & 4.280 & 6.029 & 5.478 & 4.427 & 3.569 \\
\hline Profile 3 & 27 & 4.475 & 5.434 & 3.924 & 5.883 & 6.571 & 4.574 \\
\hline Profile 4 & 30 & 3.497 & 3.891 & 6.073 & 6.345 & 6.378 & 4.243 \\
\hline Profile 5 & 3 & 7.141 & 7.591 & 3.928 & 5.947 & 5.378 & 4.852 \\
\hline
\end{tabular}

Note. $\mathrm{NE}=$ negative emotionality; $\mathrm{N}=$ neuroticism; $\mathrm{E}=$ extraversion; $\mathrm{O}=$ openness; $\mathrm{A}=$ agreeableness; $\mathrm{C}=$ conscientiousness. Bold represents the best-fitting solution. 


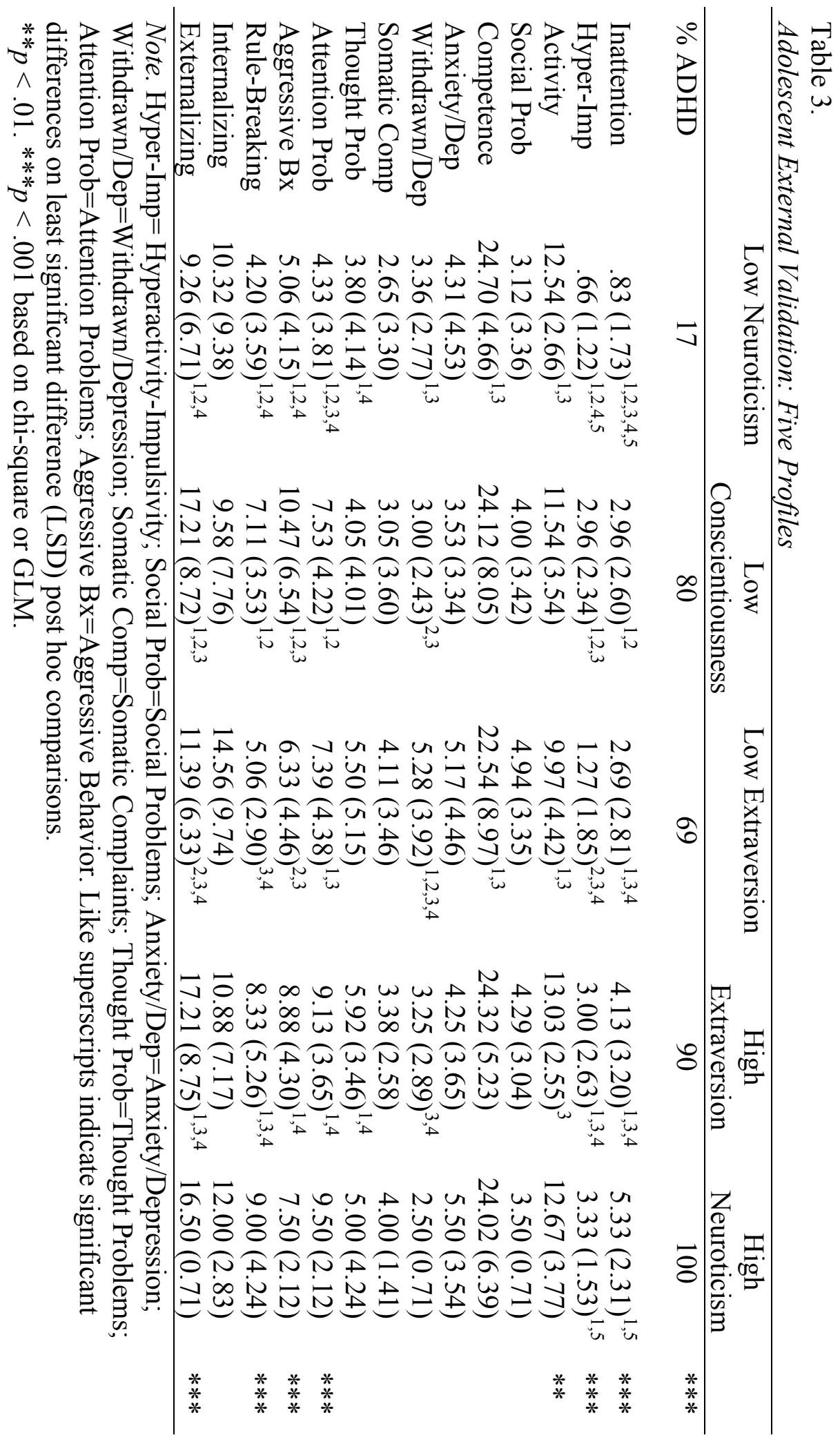


Table 4.

Comparisons of Relative Percentage of Individuals Falling into Each Profile Through Adolescence

\begin{tabular}{lccc}
\hline & Preschool & Childhood & Adolescence \\
\hline Low Neuroticism & $48 \%$ & $37 \%$ & $53 \%$ \\
High Extraversion & $18 \%$ & $38 \%$ & $17 \%$ \\
High Neuroticism & $5 \%$ & $1 \%$ & $2 \%$ \\
\hline
\end{tabular}




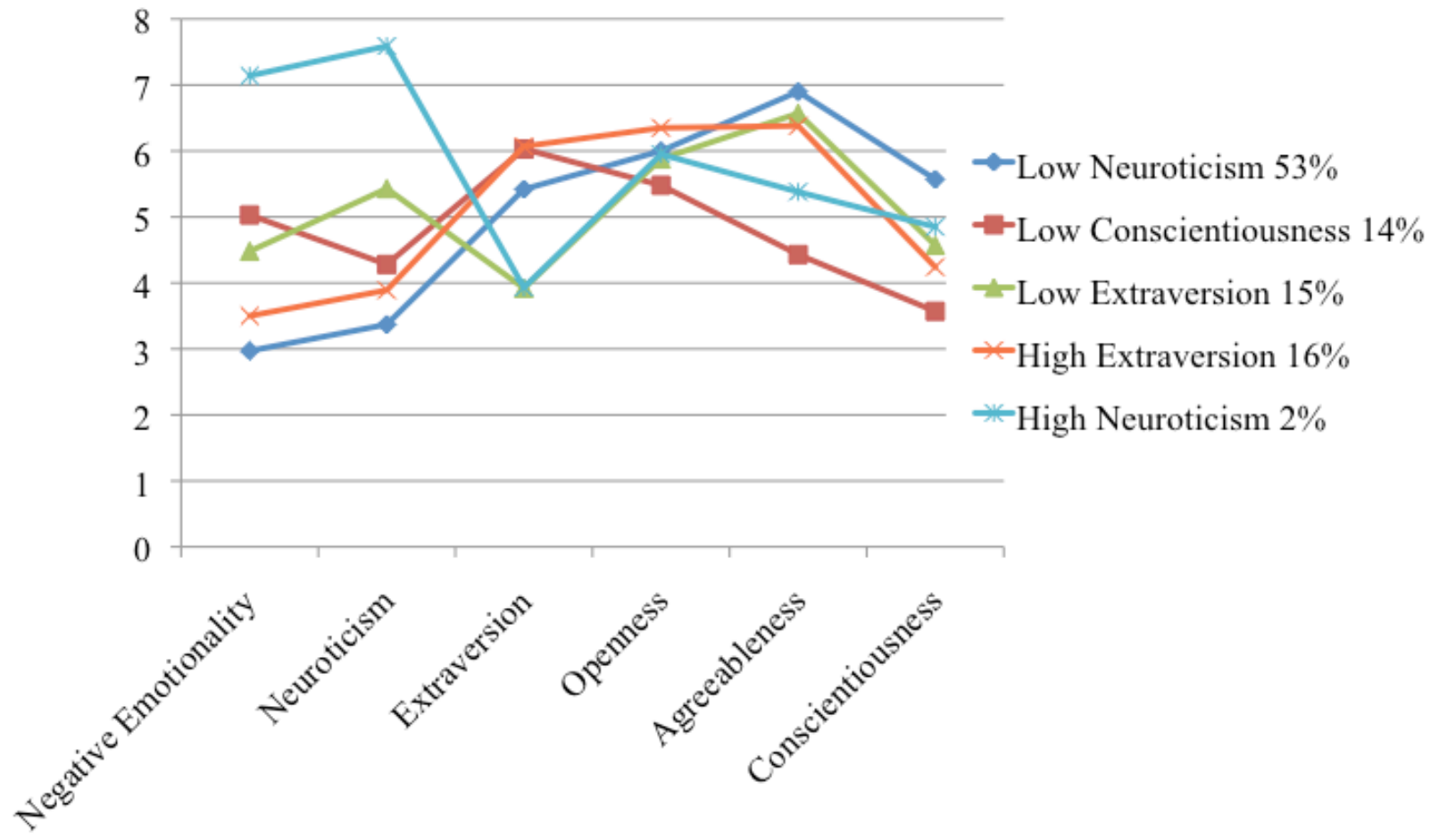

Figure 1. Five-profile solution in Adolescents 


\section{Chapter Four: Study 2- Young Adults Methods}

\section{$\underline{\text { Participants }}$}

Young adult participants were 287 undergraduates (97 males) age 18 to 24 years. Thirty percent identified themselves as ethnic or racial minorities. Forty-six percent met diagnostic criteria for ADHD based on self-report.

$\underline{\text { Recruitment and Identification }}$

The young adult sample included undergraduates from a large Southern/Midwestern university who volunteered to take part in the study in exchange for course credit with over recruitment of individuals with attention problems based on use of cut offs on a preliminary screening measure. It should be noted that individuals with all levels of ADHD symptoms were allowed to participate, but toward the end of data collection, individuals with high levels of self reported ADHD symptoms were preferentially invited to participate to allow for increased power to detect ADHD relevant effects and trait groups. All participants completed informed consent procedures consistent with institutional IRB, NIH, and APA guidelines. At the initial visit, participants were screened for the presence of a primary sensorimotor handicap, frank neurological disorder (e.g., seizure disorders, brain tumor, cerebral palsy, hydrocephalus, head injury with loss of consciousness), pervasive developmental disorder (i.e., autism, Asperger's, Rett's, childhood disintegrative disorder), frank psychosis (i.e., schizophrenia, hallucinations, delusions), diagnosed mental retardation, or the use of non-stimulant medication for ADHD.

Participants who did not endorse any of the previous criteria were invited to come back for a second laboratory visit a few weeks later during which time they completed measures of ADHD symptoms, temperament and personality traits, and comorbid disorders. ADHD diagnostic criteria, for this study, was based on self report endorsement of 5 or more symptoms 
of inattention, hyperactivity-impulsivity, or both, based on the ADHD Rating Scale. Where possible, this was validated using another informant report. Thirty-two percent of the participants had another informant report available, usually a parent or a friend. Of those with other informant report available, only $13 \%$ exhibited significant discrepancies in reports of inattentive ADHD symptoms, as operationalized as a 3-point or greater discrepancy between self and other report in this domain, while only $22 \%$ exhibited significant discrepancies in self and other reports of hyperactive-impulsive ADHD symptoms, operationalized in the same way, providing some support for the reliability of self report of ADHD symptoms.

\section{$\underline{\text { Measures }}$}

\section{$\underline{\text { ADHD Symptoms }}$}

Young adults completed the age appropriate version of the ADHD rating scale (Barkley, 2011). The rating scale includes 18 items that are consistent with DSM-IV diagnostic criteria for ADHD. Participants used a 4-point Likert scale, ranging from 0 (Never or rarely) to 3 (Very

often), to rate their symptom severity and level of impairment over the past 6 months. Total, inattentive, and hyperactive-impulsive symptom sums will be used.

\section{Comorbid Adult Diagnoses}

The Adult Self-Report (ASR; Achenbach \& Rescorla, 2003) will be used to assess social and emotional functioning. The ASR consists of 123 items rated on a 3-point scale: $0=$ Not True, $1=$ Somewhat or Sometimes True, $2=$ Very True or Often True. This instrument yields standardized scores on anxiety/depression, withdrawn symptoms, somatic complaints, thought problems, attention problems, aggressive behavior, rule-breaking behavior, intrusive symptoms, avoidant personality problems, and antisocial personality problems. Both raw and t-scores will be utilized. 


\section{Temperament and Personality Traits}

Participants completed the NEO-Five Factor Inventory-3 (NEO-FFI-3; McCrae \& Costa, 2007), a 60-item instrument that reliably and validly assesses the Big Five Factors of personality (i.e., Neuroticism, Extraversion, Openness, Agreeableness, and Conscientiousness) in adults ages 12 to 99. Participants used a 5-point Likert scale, ranging from 0 (Strongly disagree) to 4 (Strongly agree) to rate themselves of various items assessing their personality (e.g., neuroticism, "at times I have felt bitter and resentful;" agreeableness, "I try to be courteous to everyone I meet;" conscientiousness, "I keep my belongings neat and clean;" extraversion, "I like to have a lot of people around me;" openness, "I have a lot of intellectual curiousity").

Participants also completed a short form of the Adult Temperament Questionnaire (ATQ; Evans \& Rothbart, 2007). The short form of the ATQ consists of 77 items describing temperament characteristics. The questionnaire instructions consist of asking the individual to rate how well the statements describe the individual on a scale from 1 (almost always untrue) to 5 (almost always true), yielding 10 scales assessing negative affect ("It doesn't take very much to make feel frustrated or irritated"), extraversion/surgency (“I usually like to talk a lot"), and effortful control ("If I think of something that needs to be done, I usually get right to work on $i t$ '). The questionnaire is reliable and valid for use with young adults (Evans \& Rothbart, 2007). Likert scores for all of the items of a particular scale are summed and divided by the total number of items belonging to that factor scale in order to obtain an overall factor score.

\section{$\underline{\text { Data Analysis }}$}

The same data analytic strategy utilized in adolescents was also utilized in young adults. It should be noted that in the young adult sample, latent profile analysis was conducted on negative affect, surgency, effortful control, neuroticism, extraversion, conscientiousness, agreeableness, 
and openness. Minimal missingness was addressed using robust full information maximum likelihood estimation (FIML; that is, direct fitting) in Mplus (Múthen \& Múthen, 1998-2007), a method of directly fitting models to raw data without imputing data (McCartney, Burchinal, \& Bub, 2006). In general, each variable was missing $4 \%$ or less of data points.

\section{Chapter Five: Study 2- Young Adults Results}

\section{$\underline{\text { Latent Profile Analysis }}$}

Latent profile models containing one through five profiles were fit to all traits to exhaust the available models. Significant improvements in fit occurred as the number of profiles increased up to five profiles (Table 5). Thus, the five-profile model exhibited the lowest log likelihood, AIC, and BIC, as well as the highest entropy and seemed to be the best fitting model.

Descriptive statistics for personality traits within each profile for each solution are shown in Table 6 and depicted graphically in Figure 2. As shown in Table 6 and Figure 2, Profile $1(n=$ 34) was labeled "high extraversion," as this group exhibited relatively higher levels of surgency and extraversion. Profile $2(n=39)$ was characterized by relatively higher levels of negative affect and neuroticism, as well was lower levels of effortful control and conscientiousness, and was labeled "high neuroticism." Profile $3(n=13)$ exhibited relatively lower levels of surgency and extraversion, and was labeled "low extraversion." Profile $4(n=123)$ was labeled "low openness," as relatively lower levels of openness characterized this group. Profile $5(n=78)$ was characterized by relatively lower levels of negative affect and neuroticism, as well as relatively higher levels of effortful control and conscientiousness, and was labeled "low neuroticism"

As shown in Table 7, the percentage of young adults with ADHD falling into each group significantly varied across the five profiles, $\chi^{2}(4)=60.57, p=.000$; young adults in the high extraversion, high neuroticism, and low extraversion profiles were particularly likely to be 
diagnosed with ADHD compared with the low openness and low neuroticism profiles, based on over half (50\%) of the group being diagnosed with ADHD.

\section{Comparison with Preschool and Childhood Profiles}

As shown in Table 8, the relative percentage of individuals falling into each profile significantly varied preschool, middle childhood, and young adult groups, $\chi^{2}(12)=247.72, p=$ .000. Based on study hypotheses that a relatively larger percentage of individuals would fall into the high neuroticism group in young adults, compared to preschool and childhood, targeted posthoc comparisons were examined for the high neuroticism profile between preschool and young adulthood, $\chi^{2}(1)=.18, p=.669$, and between middle childhood and young adulthood, $\chi^{2}(1)=7.81, p=.005$. These results suggest, that in line with hypotheses, a relatively larger percentage of individuals in young adulthood fell into the high neuroticism profile compared to middle childhood; however, inconsistent with hypotheses, no significant differences were found between preschool and young adulthood.

\section{External Validation of Profiles}

The profiles were next externally validated via a series of multivariate GLMs that examined young adult profile differences in self-reported 1) ADHD symptoms and 2) comorbid internalizing and externalizing problems. The overall multivariate GLM examining young adult profile differences in self-reported inattention and hyperactivity-impulsivity was significant, $F(8$, $520)=14.82, p=.000$. Individual GLM identified significant differences in both self-report inattentive symptoms, $F(4,260)=32.09, p=.000$, and hyperactive-impulsive symptoms, $F(4$, $260)=21.20, p=.000$. Based on post-hoc least significant difference (LSD) tests, high extraversion and high neuroticism profiles exhibited significantly higher levels of both 
inattentive and hyperactive-impulsive symptoms, while the low neuroticism profile had significantly lower levels of inattentive symptoms, compared to all other profiles (Table 7).

The overall multivariate GLM examining young adult profile differences in self-report comorbid internalizing and externalizing problems was also significant, $F(56,948)=6.44, p=$ .000. Individual GLM identified significant differences in anxious/depressed symptoms, $F(4$, $247)=46.88, p=.000$, withdrawn symptoms, $F(4,247)=33.66, p=.000$, somatic complaints, $F(4,247)=23.79, p=.000$, thought problems, $F(4,247)=25.19, p=.000$, attention problems, $F(4,247)=51.60, p=.000$, aggressive behavior, $F(4,247)=29.35, p=.000$, rule-breaking, $F(4$, $247)=16.50, p=.000$, intrusive symptoms, $F(4,247)=18.10, p=.000$, avoidant personality problems, $F(4,247)=45.76, p=.000$, and antisocial personality problems, $F(4,247)=18.34, p$ $=.000$. Based on post-hoc LSD tests, the high neuroticism and low extraversion profiles exhibited significantly higher levels of anxiety and depression (Table 7). The low extraversion profile additionally exhibited significantly highest levels of withdrawn symptoms compared to all other profiles, and the high neuroticism profile also exhibited significantly increased levels of withdrawn symptoms compared to the high extraversion, low neuroticism, and low openness profiles. These two profiles also had significantly higher somatic complaints and thought problems, compared to the other profiles. The high extraversion, high neuroticism, and low extraversion profiles exhibited significantly higher levels of attention problems. The high neuroticism profile exhibited significantly higher levels of aggressive behavior, rule-breaking, intrusive symptoms, and both avoidant and antisocial personality problems compared to various other groups (see Table 7). The high extraversion profile exhibited significantly higher levels of just rule-breaking, intrusive symptoms, and antisocial personality problems compared to various other profiles. The low extraversion profile also exhibited significantly higher levels of avoidant 
personality problems, compared to all other profiles. Overall, the low extraversion profile exhibited higher internalizing problems, the high extraversion profile exhibited higher externalizing problems, and the high neuroticism profile exhibited higher comorbid problems, compared to other profiles, whereas the low neuroticism and low openness profiles exhibited fewer comorbid problems, compared to other profiles. 
Table 5 .

Latent Profile Analysis Fit Indices: Young Adults

\begin{tabular}{lcccc}
\hline Profile & Log likelihood & AIC & BIC & Entropy \\
\hline 1-profile & -5650.015 & 11332.029 & 11390.581 & ----- \\
2-profile & -5504.849 & 11059.699 & 11151.186 & 0.738 \\
3-profile & -5453.778 & 10975.556 & 11099.978 & 0.753 \\
4-profile & -5420.703 & 10927.406 & 11084.764 & 0.748 \\
5-profile & $\mathbf{- 5 3 9 1 . 2 9 1}$ & $\mathbf{1 0 8 8 6 . 5 8 2}$ & $\mathbf{1 1 0 7 6 . 8 7 5}$ & $\mathbf{0 . 8 0 2}$
\end{tabular}

Note. AIC $=$ Akaike's information criteria; $\mathrm{BIC}=$ Bayes information criteria. Boldface indicates the best-fitting models. 
Table 6.

Latent Profile Solutions Using Young Adult Traits: Descriptive Statistics

\begin{tabular}{lccccccccc}
\hline Solution & $n$ & NA & SUR & EC & N & E & O & A & C \\
\hline \multicolumn{1}{l}{ Five-profile solution } \\
Profile 1 & 34 & 3.698 & $\mathbf{5 . 4 7 3}$ & 3.893 & 21.091 & $\mathbf{3 8 . 3 0 5}$ & 33.860 & 31.461 & 28.554 \\
Profile 2 & 39 & $\mathbf{4 . 6 2 3}$ & 4.392 & $\mathbf{3 . 5 4 8}$ & $\mathbf{3 3 . 0 6 1}$ & 24.624 & 34.110 & 31.164 & $\mathbf{2 5 . 1 0 6}$ \\
Profile 3 & 13 & 4.617 & $\mathbf{3 . 3 8 1}$ & 5.006 & 29.634 & $\mathbf{1 8 . 1 2 5}$ & 36.920 & 36.558 & 34.404 \\
Profile 4 & 123 & 3.810 & 4.135 & 4.288 & 21.729 & 29.803 & $\mathbf{2 8 . 9 6 3}$ & 33.057 & 29.802 \\
Profile 5 & 78 & $\mathbf{3 . 2 1 1}$ & 5.019 & $\mathbf{5 . 1 4 8}$ & $\mathbf{1 3 . 5 2 2}$ & 36.183 & 31.791 & 37.187 & $\mathbf{3 5 . 8 3 0}$ \\
\hline
\end{tabular}
Note. NA = negative affect; SUR = surgency; EC = effortful control; N = neuroticism; E =
extraversion; O= openness; A = agreeableness; C = conscientiousness. Bold represents the best-
fitting solution.




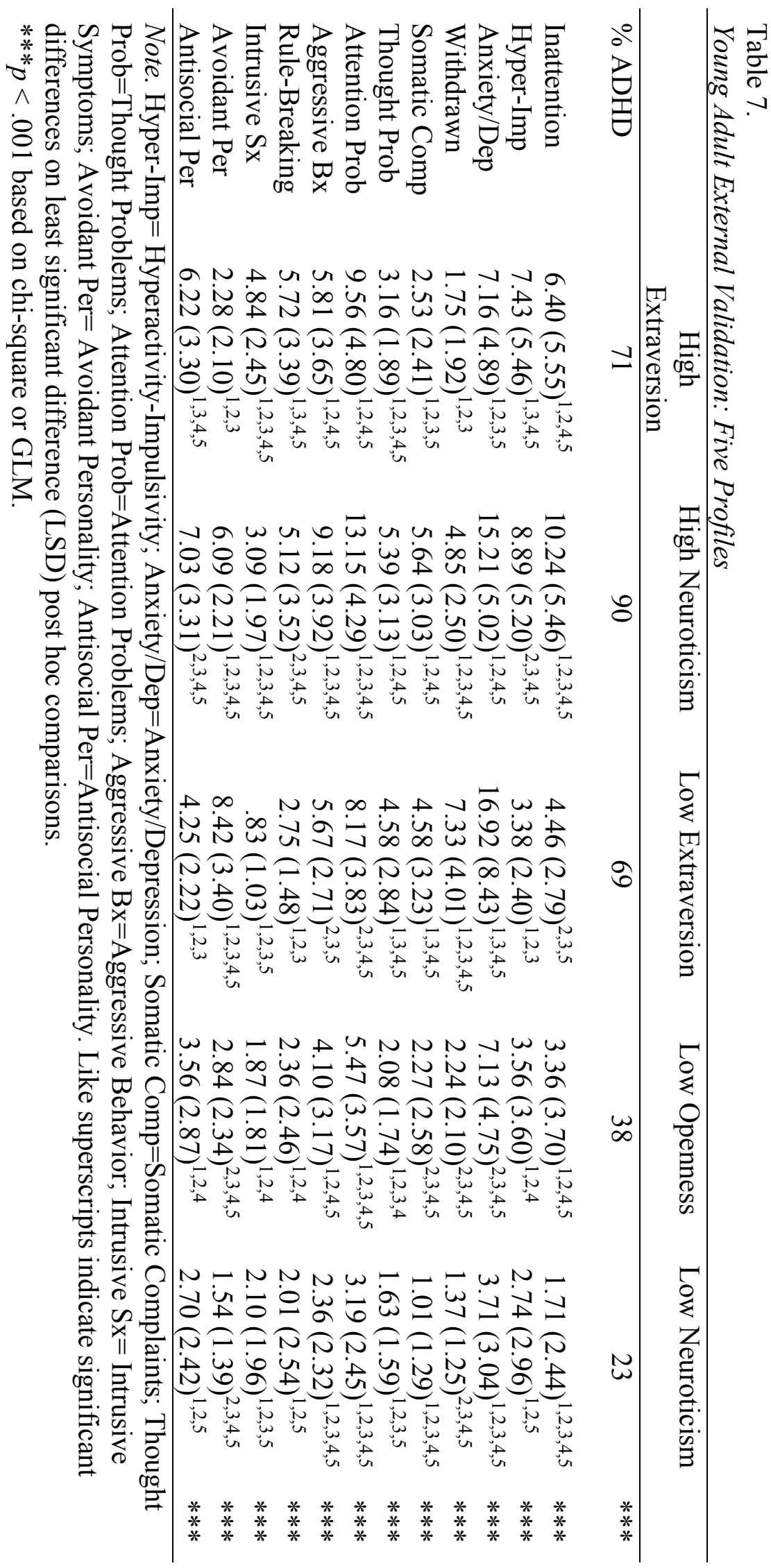




\section{Table 8 .}

Comparisons of Relative Percentage of Individuals Falling into Each Profile Through Young Adulthood

\begin{tabular}{lcccc}
\hline & Preschool & Childhood & Adolescence & $\begin{array}{c}\text { Young } \\
\text { Adulthood }\end{array}$ \\
\hline Low Neuroticism & $48 \%$ & $37 \%$ & $53 \%$ & $27 \%$ \\
High Extraversion & $18 \%$ & $38 \%$ & $17 \%$ & $12 \%$ \\
High Neuroticism & $5 \%$ & $1 \%$ & $2 \%$ & $14 \%$ \\
\hline
\end{tabular}




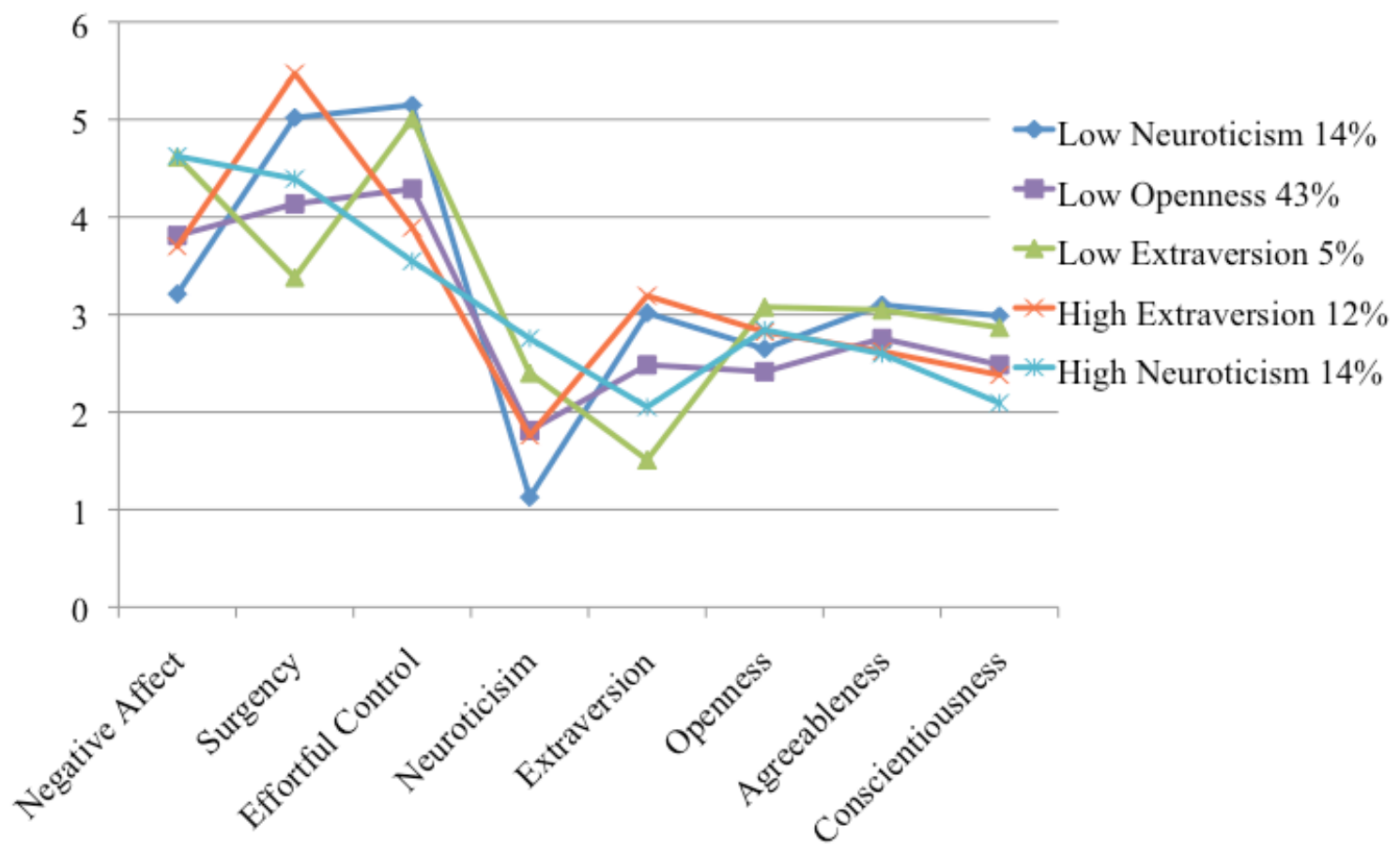

Figure 2. Five-profile solution in Young Adults 


\section{Chapter Six: Discussion}

While prior work has examined the utility of using a person-centered trait-based approach to parsing ADHD in preschool (Martel, 2016) and childhood (Martel et al., 2010), trait-based profiles had yet to be examined in adolescence and young adulthood, which was the goal of the current study. The current study examined person-centered trait-based profiles in adolescents and young adults in order to evaluate their similarity with trait-based profiles in preschoolers and school-age children, as well as externally validated those profiles in adolescence and young adulthood through examination of mean differences in profile levels of comorbid internalizing and externalizing problems. Results suggested at least three consistent trait-based profiles related to ADHD within adolescents and young adults: low extraversion, high extraversion, and high neuroticism profiles. These profiles were largely similar to those found in preschool and middle childhood and demonstrated similar comorbidity patterns; namely, the low extraversion profile exhibited higher internalizing problems, the high extraversion profile exhibited higher externalizing problems, and the small high neuroticism profile exhibited descriptively higher levels of all comorbid problems.

While five profiles were supported in both adolescents and young adults, with at least three groups characterizing ADHD, there were some differences across age groups. In adolescence, individuals with ADHD fell predominately into four groups: high extraversion, low extraversion, low conscientiousness, and high neuroticism profiles. However, in young adults, individuals with ADHD fell predominately into three groups: high extraversion, low extraversion, and high neuroticism profiles. In young adults, the profile characterized solely by low conscientiousness no longer emerged; rather, the high 
neuroticism group now also exhibited lower levels of conscientiousness. These findings suggest that adults with ADHD-related problems may be characterized by both low consciousness and high neuroticism. This is in line with prior work suggesting that conscientiousness tends to decline from late childhood to adolescence and then increase during young adulthood (Costa, McCrae, \& Siegler, 1999; Roberts, Walton, \& Viechtbauer, 2006; Soto et al., 2011). It is possible that low conscientiousness might improve in some individuals due to neural development, perhaps except for those with high neuroticism, in line with prior work suggesting interactions between negative affect and conscientiousness (Eisenberg et al., 1996; Martel \& Nigg, 2006; Martel, Gremillion, \& Roberts, 2012). Overall, the three groups found across adolescence and adulthood, namely high extraversion, low extraversion, and high neuroticism, suggest the importance of affective and emotion regulation processes in ADHD, perhaps particularly in older individuals, as has been suggested in recent theory of ADHD (Martel, 2009; Wehmeier, Schacht, \& Barkley, 2010). Furthermore, this could be viewed as consistent with cortical immaturity findings in ADHD (Shaw et al., 2007) which might suggest that in adolescence and adulthood individuals with ADHD are still working on mastering emotion regulation through development of cortical-limbic connectivity (Casey et al., 2008; Fair et al., 2010).

Counter to hypotheses, results suggested that a significantly larger percentage of individuals fell into the high neuroticism profile during preschool, compared to adolescence, but -- in line with hypotheses -- a significantly larger percentage of young adults fell into the high neuroticism profile compared to middle childhood. This could be due to the fact that the preschool sample was over-recruited for not only ADHD, but 
ODD as well, a disorder characterized by higher levels of negative affect (Stringaris, Maughan, \& Goodman, 2010). Furthermore, the low conscientiousness group seen in preschool through adolescence seemed to be absorbed into the high neuroticism group in adulthood. This could be due to the debilitating role of dysregulated neuroticism in adulthood (Lahey, 2009).

Results suggested the five profiles in adolescence exhibited distinct comorbidity patterns. In adolescence, although the high neuroticism profile was a small group of individuals, these individuals seem to be the most impaired in regard to exhibiting higher levels of both internalizing (i.e. thought problems, intrusive symptoms, avoidant personality problems) and externalizing (i.e. aggressive behavior, rule-breaking, antisocial personality problems) comorbid problems. The low conscientiousness and high extraversion profiles exhibited relatively higher levels of comorbid externalizing problems, including aggression and rule-breaking. While the low extraversion profile exhibited lower levels of hyperactivity-impulsivity, this profile exhibited increased withdrawal and depression. The low neuroticism profile exhibited lower levels of comorbid internalizing and externalizing problems. Therefore, individuals with extremely high neuroticism might be at risk for multiple forms of psychopathology, consistent with work suggesting that negative emotionality might explain the p-factor, or general factor, of psychopathology (Tackett et al., 2013). In contrast, low conscientiousness and high extraversion might be uniquely associated with externalizing problems (Krueger, 2002; Martel, 2009), and low extraversion, or positive affect, might put individuals at risk for internalizing problems (Clark \& Watson, 1991). 
The five profiles in young adulthood exhibited a similar pattern of distinct comorbidities. The small high neuroticism, the high extraversion, and the low extraversion profiles exhibited similar patterns of high levels of all problems, high externalizing problems, and high internalizing problems, respectively, while the low neuroticism profile exhibited low levels of comorbid problems. However, in addition, there was a low openness profile that also exhibited low levels of most comorbid problems, although this group exhibited higher levels of anxiety and depression compared to the low neuroticism profile.

Overall, across development in cross-sectional samples from preschool to young adulthood, a high extraversion group emerged within ADHD, and this group seemed at risk for externalizing problems (Martel et al., 2010; 2016). In addition, a small group of individuals with high neuroticism (and, for adults, also low conscientiousness) emerged across developmental periods which were at risk for all types of comorbidity (Martel et al., 2010; 2016). For preschool through school-age children, a separate group with low conscientiousness also emerged that exhibited higher levels of externalizing problems. Finally, across childhood, adolescence, and young adulthood, individuals with ADHD and low extraversion exhibited increased internalizing problems (Martel et al., 2010), possibly in line with a sluggish cognitive tempo group of children with more pure inattentive symptoms within ADHD who are also at increased risk for depression (Barkley, 2013; Becker et al., 2014; Milich, Balentine, \& Lynam, 2001). A low extraversion profile did not emerge in preschool, which suggest that introversion might be less important in preschool. This could be related to the fact that introversion seems to be a risk factor for depression, and depression is practically nonexistent in preschool. 
Therefore, this work suggests that high extraversion, high neuroticism, or low conscientiousness in individuals with ADHD might be good markers for risk for comorbid externalizing problems, while low extraversion within ADHD might be a marker for internalizing comorbidity.

This work importantly suggests the possible utility of early trait measurement for predicting the course of ADHD, as well as comorbid problems, given that traits can be measured as early as infancy (Rothbart, 1986). An important future direction is examining whether trait-based profiling approaches allow for accurate prediction of longitudinal comorbidity development in individuals within ADHD. In addition, such work suggests the possibility of use of interventions targeted to trait profiles in order to decrease ADHD symptoms, as well as comorbid problems. For example, those with low extraversion could receive treatment such as behavioral activation and assertiveness training to decrease likelihood of internalizing symptoms.

While this study builds on previous work examining person-centered trait-based profiles of ADHD in preschool and childhood and extends this work into adolescence and young adulthood, it is not without limitations. This study is a first step in examining traitbased profiles within ADHD across development, as this research is cross-sectional. As a result, each sample is different, and there were some differences in measures utilized in the different age ranges. This limitation highlights the need for longitudinal work on traitprofile associations with comorbidity over time in the same group of individuals. Additionally, observational measures might provide important additional information. Finally, some of the subgroups were small, so replication in other samples is an important future direction. 
Overall, in adolescence and young adulthood, at least three trait-based profiles characterize individuals with ADHD: a high extraversion profile, a low extraversion profile, and a high neuroticism profile. These profiles exhibited similar comorbid patterns across development, such that those characterized by high neuroticism exhibit relatively higher levels of both internalizing and externalizing problems; those characterized by low extraversion exhibit relatively higher levels of internalizing problems, including withdrawal and depression; and those with high extraversion exhibit relatively higher levels of externalizing problems, including aggression and rule-breaking. Although traitbased profiles across development were largely similar, there were some important differences. The low conscientious profile no longer emerges in young adulthood. Instead, the high neuroticism profile in young adulthood also exhibits lower levels of conscientiousness. Additionally, the low extraversion profile that emerges in middle childhood, adolescents, and young adulthood, is not present in preschool. This research suggests traits might be a useful subtyping approach for ADHD, as the current subtypes of ADHD in the DSM fail to demonstrate external validity, and these trait-based profiles appear to exhibit unique comorbidity patterns. Such an approach might have useful implications for early assessment and personalized intervention for ADHD. 


\section{Appendices}

Appendix 1.

Latent Profile Solutions Using Adolescent Traits: Descriptive Statistics

\begin{tabular}{rlllllll}
\hline Solution & $n$ & $\mathrm{NE}$ & $\mathrm{N}$ & $\mathrm{E}$ & $\mathrm{O}$ & $\mathrm{A}$ & $\mathrm{C}$ \\
\hline \multicolumn{2}{l}{ Four-profile solution } & & & & & & \\
Profile 1 & 27 & 4.902 & 4.228 & 6.087 & 5.536 & 4.573 & $\mathbf{3 . 6 0 2}$ \\
Profile 2 & 121 & $\mathbf{3 . 0 3 8}$ & $\mathbf{3 . 4 4 5}$ & 5.556 & 6.096 & 6.816 & 6.096 \\
Profile 3 & 31 & 4.408 & 5.304 & 4.186 & 5.899 & $\mathbf{6 . 5 6 1}$ & 4.568 \\
Profile 4 & 3 & $\mathbf{7 . 1 3 4}$ & $\mathbf{7 . 5 8 3}$ & 3.933 & 5.945 & 5.372 & 4.848 \\
\hline
\end{tabular}

Note. $\mathrm{NE}=$ negative emotionality; $\mathrm{N}=$ neuroticism; $\mathrm{E}=$ extraversion; $\mathrm{O}=$ openness; $\mathrm{A}=$ agreeableness; $\mathrm{C}=$ conscientiousness. Bold indicates best-fitting solution. 


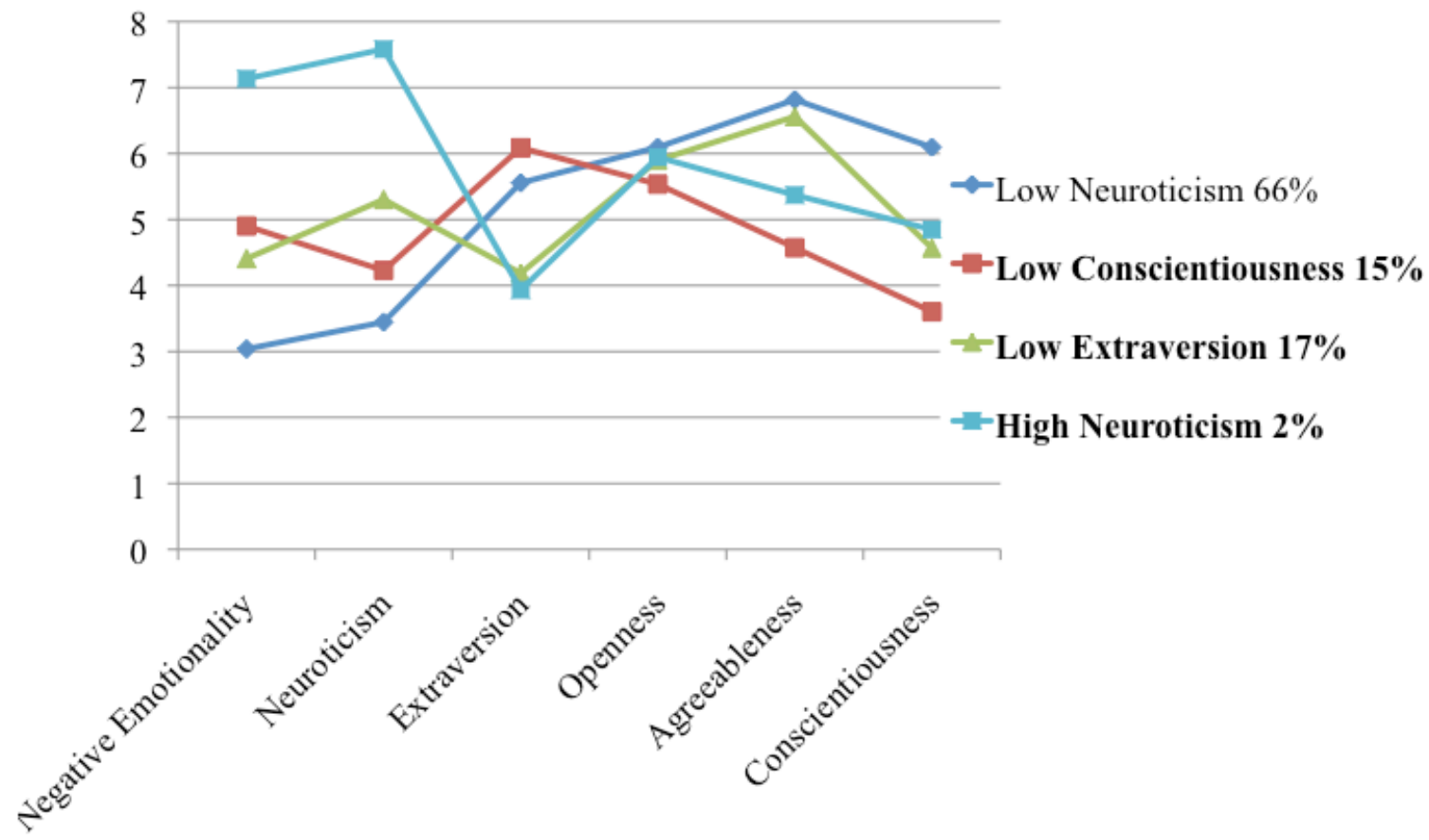

Appendix 2. Four-profile Solution in Adolescents 


\section{References}

Achenbach, T. M. (1991). Integrative guide for the 1991 CBCL/4-18, YSR, and TRF profiles. Department of Psychiatry, University of Vermont.

Achenbach, T. M., \& Rescorla, L. A. (2003). Manual for the ASEBA Adult Forms \& Profiles. Burlington, VT: University of Vermont, Research Center for Children, Youth, \& Families.

American Psychiatric Association. (2013). Diagnostic and statistical manual of mental disorders (5th edition). Washington, DC: American Psychiatric Association.

Barkley, R. A. (2006). Attention-deficit hyperactivity disorder, 3rd ed.: A handbook for diagnosis and treatment. New York, NY, US: Guilford Press.

Barkley, R. A. (2011). Barkley Adult ADHD Rating Scale-IV (BAARS-IV). Guilford Press.

Barkley, R. A. (2012). Distinguishing sluggish cognitive tempo from attentiondeficit/hyperactivity disorder in adults. Journal of Abnormal Psychology, 121(4), 978.

Barkley, R. A. (2013). Distinguishing sluggish cognitive tempo from ADHD in children and adolescents: executive functioning, impairment, and comorbidity. Journal of Clinical Child \& Adolescent Psychology, 42(2), 161-173.

Barkley, R. A. (2014). Attention-deficit hyperactivity disorder, $4^{\text {th }}$ ed.: A handbook for diagnosis and treatment. New York, NY, US: Guilford Press.

Barkley, R. A., Anastopoulos, A. D., Guevremont, D. C., \& Fletcher, K. E. (1991). Adolescents with ADHD: Patterns of behavioral adjustment, academic 
functioning, and treatment utilization. Journal of The American Academy of Child \& Adolescent Psychiatry, 30(5), 752-761. doi:10.1097/00004583-19910900000009

Becker, S. P., Luebbe, A. M., \& Langberg, J. M. (2014). Attention-deficit/hyperactivity disorder dimensions and sluggish cognitive tempo symptoms in relation to college students' sleep functioning. Child Psychiatry \& Human Development, 45(6), 675685.

Biederman, J., Petty, C. R., Evans, M., Small, J., \& Faraone, S. V. (2010). How persistent is ADHD? A controlled 10-year follow-up study of boys with ADHD. Psychiatry research, 177(3), 299-304.

Casey, B. J., Jones, R. M., \& Hare, T. A. (2008). The adolescent brain. Annals of the New York Academy of Sciences, 1124(1), 111-126.

Caspi, A., Block, J., Block, J. H., Klopp, B., Lynam, D., Moffitt, T. E., \& StouthamerLoeber, M. (1992). A" common-language" version of the California Child Q-Set for personality assessment. Psychological Assessment, 4(4), 512.

Chhabildas, N., Pennington, B. F., \& Willcutt, E. G. (2001). A comparison of the neuropsychological profiles of the DSM-IV subtypes of ADHD. Journal of abnormal child psychology, 29(6), 529-540.

Clark, L. A., \& Watson, D. (1991). Tripartite model of anxiety and depression: psychometric evidence and taxonomic implications. Journal of abnormal psychology, 100(3), 316.

Conners, C. K. (1997). Conners' Rating Scales--revised: User's Manual. Multi-Health Systems, Incorporated. 
Costa, P. T., McCrae, R. R., \& Siegler, I. C. (1999). Continuity and change over the adult life cycle: Personality and personality disorders. Personality and psychopathology, 129-154.

De Bolle, M., Beyers, W., De Clercq, B., \& De Fruyt, F. (2012). General personality and psychopathology in referred and nonreferred children and adolescents: An investigation of continuity, pathoplasty, and complication models. Journal of Abnormal Psychology, 121(4), 958-970.

De Fruyt, F., Bartels, M., Van Leeuwen, K. G., De Clercq, B., Decuyper, M., \& Mervielde, I. (2006). Five types of personality continuity in childhood and adolescence. Journal of Personality And Social Psychology, 91(3), 538-552. doi:10.1037/0022-3514.91.3.538

De Pauw, S. S., Mervielde, I., \& Van Leeuwen, K. G. (2009). How are traits related to problem behavior in preschoolers? Similarities and contrasts between temperament and personality. Journal of abnormal child psychology, 37(3), 309325.

DuPaul, G. J., Power, T. J., Anastopoulos, A. D., \& Reid, R. (1998). ADHD Rating Scale-IV (for Children and Adolescents): Checklists, norms, and clinical interpretation. New York: Guilford.

Eisenberg, N., Fabes, R. A., Guthrie, I. K., Murphy, B. C., Maszk, P., Holmgren, R. (1996). The relations of regulation and emotionality to problem behavior in elementary school children. Development and Psychopathology, 8, 141-162.

Evans, D. E., \& Rothbart, M. K. (2007). Developing a model for adult temperament. Journal of Research in Personality, 41(4), 868-888. 
Fair, D. A., Nigg, J. T., Iyer, S., Bathula, D., Mills, K. L., Dosenbach, N. U., ... \& Milham, M. P. (2012). Distinct neural signatures detected for ADHD subtypes after controlling for micro-movements in resting state functional connectivity MRI data. Frontiers in systems neuroscience, 6.

Fair, D. A., Posner, J., Nagel, B. J., Bathula, D., Dias, T. G. C., Mills, K. L., ... \& Nigg, J. T. (2010). Atypical default network connectivity in youth with attentiondeficit/hyperactivity disorder. Biological Psychiatry, 68(12), 1084-1091.

Faraone, S. V., \& Biederman, J. (2005). What is the prevalence of adult ADHD? Results of a population screen of 966 adults. Journal of Attention Disorders, 9(2), 384391.

Frick, P. J. (2004). Special Selection: Temperament and Childhood Psychopathology. Integrating Research on Temperament and Childhood Psychopathology: Its Pitfalls and Promise. Journal of Clinical Child and Adolescent Psychology, 33(1), 2-7. doi:10.1207/S15374424JCCP3301_1

Goth-Owens, T. L., Martinez-Torteya, C., Martel, M. M., \& Nigg, J. T. (2010).

Processing speed weakness in children and adolescents with non-hyperactive but inattentive ADHD (ADD). Child Neuropsychology, 16(6), 577-591.

Grant, J. D., Scherrer, J. F., Neuman, R. J., Todorov, A. A., Price, R. K., \& Bucholz, K. K. (2006). A comparison of the latent class structure of cannabis problems among adult men and women who have used can- nabis repeatedly. Addiction, 101, $1133-1142$.

Hart, E. L., Lahey, B. B., Loeber, R., Applegate, B., Green, S. M., \& Frick, P. J. (1995). Developmental change in attention-deficit hyperactivity disorder in boys: A four- 
year longitudinal study. Journal of Abnormal Child Psychology, 23(6), 729-749. doi:10.1007/BF01447474

Hopwood, C. J., Donnellan, M. B., Blonigen, D. M., Krueger, R. F., McGue, M., Iacono, W. G., \& Burt, A. (2012). Genetic and environmental influences on personality trait stability and growth during the transition to adulthood: A three wave longitudinal study. Journal of Personality and Social Psychology, 100(3), 545556.

Insel, T., Cuthbert, B., Garvey, M., Heinssen, R., Pine, D. S., Quinn, K., \& ... Wang, P. (2010). Research domain criteria (RDoC): Toward a new classification framework for research on mental disorders. The American Journal of Psychiatry, 167(7), 748-751. doi:10.1176/appi.ajp.2010.09091379

John, O. P., Caspi, A., Robins, R. W., Moffitt, T. E., \& Stouthamer-Loeber, M. (1994). The "little five": Exploring the nomological network of the five-factor model of personality in adolescent boys. Child Development, 65, 160-178.

Karalunas, S. L., Fair, D., Musser, E. D., Aykes, K., Iyer, S. P., \& Nigg, J. T. (2014). Subtyping attention-deficit/hyperactivity disorder using temperament dimensions: Toward biologically based nosologic. JAMA Psychiatry, 71(9), 1015-1024. doi:10.1001/jamapsychiatry.2014.763

Kline, R. B. (2005). Principles and practice of structural equation mod- eling (2nd ed.). New York: Guilford Press.

Krueger, R. F. (2002). Personality from a realist's perspective: Personality traits, criminal behaviors, and the externalizing spectrum. Journal of Research in Personality, $36(6), 564-572$. 
Krueger, R. F., \& Markon, K. E. (2014). The Role of the DSM-5 Personality Trait Model in Moving Toward a Quantitative and Empirically Based Approach to Classifying Personality and Psychopathology. Annu Rev Clin Psychol, 10, 477-501. doi:

10.1146/annurev-clinpsy-032813-153732

Lahey, B. B. (2009). Public health significance of neuroticism. American Psychologist, 64(4), 241.

Lahey, B. B., Pelham, W. E., Loney, J., Lee, S. S., \& Willcutt, E. (2005). Instability of the DSM-IV Subtypes of ADHD From Preschool Through Elementary School. Archives of General Psychiatry, 62(8), 896-902. doi:10.1001/archpsyc.62.8.896

Mannuzza, S., \& Klein, R. G. (1999). Adolescent and adult outcomes in attention deficit/hyperactivity disorder. In: H. C. Quay, \& A. E. Hogan (Eds.), Handbook of Disruptive Behavior Disorder (pp. 279-294). New York: Kluwer Academic/Plenum Publishers.

Markon, K. E., Krueger, R. F., \& Watson, D. (2005). Delineating the Structure of Normal and Abnormal Personality: An Integrative Hierarchical Approach. Journal of Personality and Social Psychology, 88(1), 139-157. doi:10.1037/00223514.88 .1 .139

Martel, M. M. (2009). Research review: A new perspective on attention-deficit hyperactivity disorder: Emotion dysregulation and trait models. Journal of Child Psychology And Psychiatry, 50(9), 1042-1051. doi:10.1111/j.14697610.2009.02105.x

Martel, M. M., Goth-Owens, T., Martinez-Torteya, C., \& Nigg, J. T. (2010). A personcentered personality approach to heterogeneity in attention-deficit/hyperactivity 
disorder (ADHD). Journal of Abnormal Psychology, 119(1), 186-196. doi: $10.1037 / \mathrm{a} 0017511$

Martel, M. M., Gremillion, M. L., \& Roberts, B. (2012). Temperament and common disruptive behavior problems in preschool. Personality and individual differences, 53(7), 874-879.

Martel, M. M., \& Nigg, J. T. (2006). Child ADHD and personality/temperament traits of reactive and effortful control, resiliency, and emotionality. Journal of Child Psychology And Psychiatry, 47(11), 1175-1183. doi:10.1111/j.14697610.2006.01629.x

Martel, M. M., von Eye, A., \& Nigg, J. (2012). Developmental differences in structure of attention-deficit/hyperactivity disorder (ADHD) between childhood and adulthood. International Journal of Behavioral Development, 36(4), 279-292. doi: $10.1177 / 0165025412444077$

McBurnett, K., Pfiffner, L. J., \& Frick, P. J. (2001). Symptom properties as a function of ADHD type: An argument for continued study of sluggish cognitive tempo. Journal of Abnormal Child Psychology, 29(3), 207-213. doi:10.1023/A:1010377530749

McCartney, K., Burchinal, M. R., \& Bub, K. L. (2006). Best practices in quantitative methods for developmentalists. Monographs of the Society for Research in Child Development, 71(3), 1-145.

McCrae, R. R., \& Costa, P. T. (1987). Validation of the five-factor model of personality across instruments and observers. Journal of Personality and Social Psychology, $52,81-90$. 
McCrae, R. R., \& Costa Jr, P. T. (2007). Brief versions of the NEO-PI-3. Journal of Individual Differences, 28(3), 116.

McCrae, R. R., Costa Jr, P. T., Terracciano, A., Parker, W. D., Mills, C. J., De Fruyt, F., \& Mervielde, I. (2002). Personality trait development from age 12 to age 18: Longitudinal, cross-sectional and cross-cultural analyses. Journal of personality and social psychology, 83(6), 1456.

Milich, R., Balentine, A. C., \& Lynam, D. R. (2001). ADHD combined type and ADHD predominantly inattentive type are distinct and unrelated disorders. Clinical Psychology: Science and Practice, 8(4), 463-488.

Miller, C. J., Miller, S. R., Newcorn, J. H., \& Halperin, J. M. (2008). Personality characteristics associated with persistent ADHD in late adolescence. Journal of Abnormal Child Psychology, 36(2), 165-173. doi:10.1007/s10802-007-9167-7

Muthe' n, L. K., \& Muthe' n, B. O. (1998-2007). Mplus user's guide (4th ed.). Los Angeles, CA: Author.

Nigg, J. T. (2006). Temperament and developmental psychopathology. Journal of Child Psychology and Psychiatry, 47(3-4), 395-422. doi:10.1111/j.14697610.2006.01612.x

Nigg, J. T., Goldsmith, H. H., \& Sachek, J. (2004). Temperament and attention deficit hyperactivity disorder: The development of a multiple pathway model. Journal of Clinical Child and Adolescent Psychology, 33(1), 42-53.

Nigg, J. T., John, O. P., Blaskey, L. G., Huang-Pollock, C. L., Willcutt, E. G., Hinshaw, S. P., \& Pennington, B. (2002). Big five dimensions and ADHD symptoms: Links 
between personality traits and clinical symptoms. Journal of Personality and Social Psychology, 83(2), 451-469. doi: Doi 10.1037//0022-3514.83.2.451

Nigg, J. T., Willcutt, E. G., Doyle, A. E., \& Sonuga-Barke, E. S. (2005). Causal Heterogeneity in Attention-Deficit/ Hyperactivity Disorder: Do We Need Neuropsychologically Impaired Subtypes?. Biological Psychiatry, 57(11), 12241230. doi:10.1016/j.biopsych.2004.08.025

Nikolas, M. A., \& Nigg, J. T. (2013). Neuropsychological performance and attentiondeficit hyperactivity disorder subtypes and symptom dimensions. Neuropsychology, 27(1), 107.

Nylund, K. L., Asparouhov, T., \& Muthe' n, B. O. (2007). Deciding on the number of classes in latent class analysis and growth mixture modeling: A Monte Carlo simulation study. Structural Equation Modeling, 14, 535-569.

Pelham, W. E., Foster, E. M., \& Robb, J. A. (2007). The economic impact of attentiondeficit/hyperactivity disorder in children and adolescents. Journal of Pediatric Psychology, 32(6), 711-727. doi:10.1093/jpepsy/jsm022

Polanczyk, G., de Lima, M., Horta, B., Biederman, J., \& Rohde, L. (2007). The worldwide prevalence of ADHD: a systematic review and metaregression analysis. American journal of psychiatry, 164(6), 942-948.

Puig-Antich, J., \& Ryan, N. (1986). Kiddie Schedule for Affective Disorders and Schizophrenia. Pittsburgh, PA: Western Psychiatric Institute.

Roberts, B. W., \& DelVecchio, W. F. (2000). The rank-order consistency of personality traits from childhood to old age: a quantitative review of longitudinal studies. Psychological bulletin, 126(1), 3. 
Roberts, B. W., Walton, K. E., \& Viechtbauer, W. (2006). Patterns of mean-level change in personality traits across the life course: a meta-analysis of longitudinal studies. Psychological bulletin, 132(1), 1.

Rothbart, M. K. (1986). Longitudinal observation of infant temperament. Developmental Psychology, 22(3), 356.

Rothbart, M. K. (1989). Temperament in childhood: A framework. In G. A. Kohnstamm, J. E. Bates, \& M. K. Rothbart (Eds.), Temperament in childhood, (59-73). Hoboken, NJ: Wiley.

Rothbart, M. K. (1991). Temperament: A developmental framework. In J. Strelau, A. Angleitner (Eds.), Explorations in temperament: International perspectives on theory and measurement, (pp. 61-74). New York, NY, US: Plenum Press.

Rothbart, M. K. (2007). Temperament, development, and personality. Current Directions in Psychological Science, 16(4), 207-212. doi:10.1111/j.1467-8721.2007.00505.x

Samuel, D. B., \& Widiger, T. A. (2008). A meta-analytic review of the relationships between the five-factor model and DSM-IV-TR personality disorders: A facet level analysis. Clinical Psychology Review, 28(8), 1326-1342. doi:

10.1016/j.cpr.2008.07.002

Shaw, P., Eckstrand, K., Sharp, W., Blumenthal, J., Lerch, J. P., Greenstein, D. E. E. A., ... \& Rapoport, J. L. (2007). Attention-deficit/hyperactivity disorder is characterized by a delay in cortical maturation. Proceedings of the National Academy of Sciences, 104(49), 19649-19654.

Shiner, R. L., Buss, K. A., McClowry, S. G., Putnam, S. P., Saudino, K. J., \& Zentner, M. (2012). What Is Temperament Now? Assessing Progress in Temperament 
Research on the Twenty-Fifth Anniversary of Goldsmith et al. (1987). Child Development Perspectives, 6(4), 436-444. doi:10.1111/j.1750-8606.2012.00254.x

Shiner, R., \& Caspi, A. (2003). Personality differences in childhood and adolescence: Measurement, development, and consequences. Journal of Child Psychology and Psychiatry, 44, 2-32.

Silberg, J. L., Miguel, V. F., Murrelle, E. L., Prom, E., Bates, J. E., Canino, G., Egger, H., \& Eaves, L. J. (2005). Genetic and environmental influences on temperament in the first year of life: The Puerto Rico Infant Twin Study (PRINTS). Twin Research and Human Genetics, 8(4), 328-336.

Soto, C. J., John, O. P., Gosling, S. D., \& Potter, J. (2011). Age differences in personality traits from 10 to 65: Big Five domains and facets in a large cross-sectional sample. Journal of personality and social psychology, 100(2), 330.

Stringaris, A., Maughan, B., \& Goodman, R. (2010). What's in a disruptive disorder? Temperamental antecedents of oppositional defiant disorder: findings from the Avon longitudinal study. Journal of the American Academy of Child \& Adolescent Psychiatry, 49(5), 474-483.

Tabachnick, B. G., \& Fidell, L. S. (2007). Using multivariate statistics (5th ed.). Boston, MA: Pearson.

Tackett, J. L. (2006). Evaluating models of the personality-psychopathology relationship in children and adolescents. Clinical Psychology Review, 26(5), 584-599. doi:10.1016/j.cpr.2006.04.003

Tackett, J. L., Lahey, B. B., Van Hulle, C., Waldman, I., Krueger, R. F., \& Rathouz, P. J. (2013). Common genetic influences on negative emotionality and a general 
psychopathology factor in childhood and adolescence. Journal of Abnormal Psychology, 122(4), 1142.

Van Leeuwen, K., Mervielde, I., De Clercq, B.J., De Fruyt, F. (2007). Extending the spectrum idea: Child personality, parenting and psychopathology. European Journal of Personality, 21, 63-89.

Wehmeier, P. M., Schacht, A., \& Barkley, R. A. (2010). Social and emotional impairment in children and adolescents with ADHD and the impact on quality of life. Journal of Adolescent Health, 46(3), 209-217. 


\section{Vita}

Tess E. Smith

\section{Education}

Bachelor of Science - Psychology, Research Focused Honors Program

Minor in Human and Development Family Studies

Purdue University, West Lafayette, IN

May 2014

\section{Professional Experience}

\section{Research}

University of Kentucky, Lexington, KY

Graduate Research Assistant for Dr. Michelle Martel

August 2014 - present

Purdue University, West Lafayette, IN

Undergraduate Research Assistant for Dr. Doug Samuel

January 2011 - May 2014

Undergraduate Research Assistant for Dr. Ximena Arriaga

August 2013 - December 2013

\section{Clinical}

Harris Psychological Services Center, Lexington, KY

Graduate Student Therapist

August 2015 - present

Managing Frustration for Children Group Therapist

August 2015 - December 2015

College of Public Health, University of Kentucky, Lexington, KY

Family Check-up Interventionist

June 2015 - present

University of Kentucky Counseling Center, Lexington, KY

Practicum-Level Individual Therapist

August 2015 - May 2016

Understanding Self and Others Interpersonal Group Therapist

January 2016 - May 2016

Understanding Self and Others Interpersonal Group Process Observer August 2015 - December 2015

University of Kentucky, Lexington, KY

Personality Assessment Practicum

February 2015 - May 2015

IQ Assessment Practicum 
November 2014 - December 2014

\section{Teaching}

University of Kentucky, Lexington, KY

Graduate Teaching Assistant

August 2015 - May 2016

$\underline{\text { Professional Publications and Presentations }}$

Publications

Smith, T. E., \& Samuel, D. B. (2016). A multi-method examination of the links between ADHD and personality disorder. Journal of Personality Disorders, 1-23.

Smith, T. E., Martel, M. M., \& DeSantis, A. D. (under review). Subjective report of side effects of prescribed and non-prescribed psychostimulant use in young adults. Substance Use and Misuse.

Smith, T. E., Martel, M. M., \& DeSantis, A. D. (under review). Gender differences in nonprescribed psychostimulant use in young adults. Substance Use and Misuse.

Gremillion, M. L., Smith, T. E., \& Martel, M. M. (under review). Verbal working memory as a longitudinal mechanism of vocabulary problems in preschoolers with ADHD. Journal of Psychopathology and Behavioral Assessment.

Smith, T. E., Lee, C. A., Martel, M. M, \& Axelrad, M. E. (under review). ODD symptom network during preschool. Journal of Abnormal Child Psychology.

Lee, C. A., Smith, T. E., \& Martel, M. M. (under review). Trait network of oppositional defiant disorder and attention-deficit/hyperactivity disorder from preschool to middle childhood. Journal of Clinical Child \& Adolescent Psychology.

Martel, M. M., Levinson, C. A., Lee, C. A., \& Smith, T. E. (in press). Impulsivity symptoms as core to the developmental externalizing spectrum. Journal of Abnormal Child Psychology.

\section{Presentations}

Smith, T. E. \& Zastrow, B. L.(2016, March) Trait-based profiles of ADHD in adolescents. In M. Martel (Chair), Affect, Personality, and Developmental Psychopathology. Symposium conducted at the $2^{\text {nd }}$ World Conference on Personality, Buzios, Brazil.

Zastrow, B. L., Smith, T. E. \& Martel, M. M. (2015, July) Emerging control and longitudinal change in ADHD symptoms during preschool. In M. Miller (Chair), Longitudinal mechanisms in $A D H D$. Symposium conducted at the International Society for Research in Child and Adolescent Psychopathology, Portland, OR. 
Smith, T. E. (2014, May). A multi-method examination of the links between ADHD and personality disorder. Poster presentation at the meeting of the Midwestern Psychological Association (MPA), Chicago, IL.

$\underline{\text { Scholastic Honors }}$

Purdue University

Honors Certification in College of Health and Human Sciences

Research Focused Honors Program

Donald R. Ottinger Award for Undergraduate Research

Dean's List

May 2014

January 2013 - May 2014

August 2012 - May 2013

August 2010 - May 2014

$\underline{\text { Society Membership }}$

Psi Chi

April 2012 - present 